\title{
Effect of Crystal Packing on H-Bond Parameters: X-Ray Structure of the Sulfadimidine'p-Chlorobenzoic Acid Co-crystal
}

\author{
Roxana LuCACIU,* Corina IoneSCu, * Alexander WILdERVANCK, ** and Mino R. CAIRA**† \\ *Department of Pharmaceutical Biochemistry and Clinical Laboratory, \\ University of Medicine and Pharmacy, "Iuliu Hatieganu”, Cluj-Napoca, Romania \\ **Department of Chemistry, University of Cape Town, Rondebosch 7701, South Africa
}

\begin{abstract}
The X-ray structure of the 1:1 co-crystal (1) between the antibacterial drug sulfadimidine (SD) and $p$-chlorobenzoic acid (PCL) is reported. Compound 1 crystallizes in the space group $P 2_{1} / c$ with $a=15.354(5) \AA, b=14.433(4) \AA, c=$ $18.732(5) \AA, \beta=94.540(5)^{\circ}$, and $Z=8$. In the two independent co-crystal units, identical $R_{2}^{2}(8)$ hydrogen-bonded motifs occur, each involving the hydrogen bond $\mathrm{SD}\left(-\mathrm{SO}_{2}-\mathrm{N}-\mathrm{H}\right) \cdots \mathrm{O}=\mathrm{C}(\mathrm{PCL})$ and the hydrogen bond $\mathrm{PCL}(\mathrm{O}-\mathrm{H}) \cdots \mathrm{N}(\mathrm{SD}$ pyrimidinyl). A significant inequality of the two $\mathrm{N} \cdots \mathrm{O}$ distances in the chemically identical $\mathrm{N}-\mathrm{H} \cdots \mathrm{O}=\mathrm{C}$ hydrogen bonds indicates that such parameters can be strongly influenced by the crystal packing factors.
\end{abstract}

(Received January 8, 2008; Accepted March 24, 2008; Published on web May 16, 2008)

Co-crystal formation is of significant current interest, especially in the context of pharmaceutical development. ${ }^{1}$ The reaction between the antibacterial sulfadimidine [4-amino- $N-(4,6-$ dimethyl-2-pyrimidinyl)benzenesulfonamide] and a series of benzoic acid derivatives, both in the solid-state and in solution, yielded 1:1 co-crystals whose properties and solid-state reactions have recently been reviewed. ${ }^{2}$ The title structure $\mathbf{1}$ (Fig. 1) is a representative member of this series, typified by the formation of the $R(8)$ hydrogen bonded motif between the cocrystallizing partners. An earlier attempt to correlate the N$\mathrm{H} \cdots \mathrm{O}$ and $\mathrm{O}-\mathrm{H} \cdots \mathrm{N}$ distances comprising this specific $R_{2}^{2}(8)$ system with $\mathrm{p} K_{\mathrm{a}}$ differences between the co-crystal partners was partially successful, but was based on the X-ray structures of a series of analogs that contained only one co-crystal molecule in the asymmetric unit. ${ }^{3}$ An examination of the title structure, however, with two molecules of the co-crystal in the asymmetric unit, allows possible effects of the crystal packing on the variability of the hydrogen bonded parameters to be distinguished.

Colorless crystals of $\mathbf{1}$ were grown by the slow evaporation of an acetonitrile solution containing an equimolar mixture of sulfadimidine and $p$-chlorobenzoic acid. As proven by PXRD

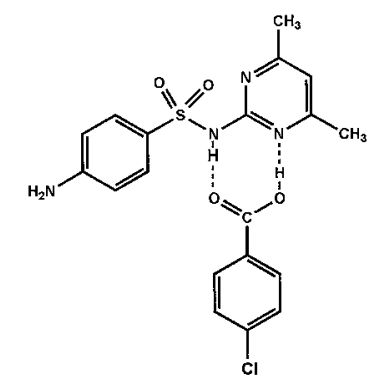

Fig. 1 Chemical structure of the sulfadimidine. $p$ chlorobenzoic acid co-crystal.

$\dagger$ To whom correspondence should be addressed.

E-mail: Mino.Caira@uct.ac.za analysis, the identical phase could also be obtained by solidstate co-grinding of the components in a ball-mill for $10 \mathrm{~min}$. Although sulfadimidine and $p$-chlorobenzoic acid yielded DSC fusion endotherms peaking at 197 and $243^{\circ} \mathrm{C}$, respectively, 1 melted at $207^{\circ} \mathrm{C}$. Co-crystal formation was also confirmed by shifts of the $\mathrm{N}-\mathrm{H}$ infrared stretching bands of pure sulfadimidine $\left(3436,3337,3236 \mathrm{~cm}^{-1}\right)$ to significantly higher frequencies in the product $\left(3469,3376,3256 \mathrm{~cm}^{-1}\right)$.

Intensity data were measured from a crystal of size $0.38 \times$ $0.38 \times 0.40 \mathrm{~mm}$ at room temperature $(294 \pm 2 \mathrm{~K})$, and were corrected for $L p$ and absorption effects. With $Z=8$, the space group $P 2_{1} / c$ requires the asymmetric unit to comprise two cocrystal units. The structure was solved by direct methods and refined by full-matrix least-squares on $F^{2}$ using SHELXL 97. All hydrogen atoms were located unequivocally in difference

Table 1 Crystal and experimental data

\begin{tabular}{ll}
\hline CCDC deposition number & 672462 \\
Formula & $\mathrm{C}_{12} \mathrm{H}_{14} \mathrm{~N}_{4} \mathrm{O}_{2} \mathrm{~S}_{-} \mathrm{C}_{7} \mathrm{H}_{5} \mathrm{ClO}_{2}$ \\
Formula weight & 434.89 \\
Crystal system & monoclinic \\
Space group & $P{ }_{1} / c$ \\
$Z$ & 8 \\
$a$ & $15.354(5) \AA$ \\
$b$ & $14.433(5) \AA$ \\
$c$ & $18.732(5) \AA$ \\
$\beta$ & $94.540(5)^{\circ}$ \\
$V$ & $4138(2) \AA^{\circ}$ \\
$D_{\mathrm{x}}$ & $1.396 \mathrm{~g} \mathrm{~cm}^{-3}$ \\
No. of reflections used & 7498 \\
$2 \theta_{\max }$ & $50.0^{\circ}$ with Mo $K_{\alpha}$ \\
$R(3983$ data, $I>2 \sigma(I))$ & 0.0386 \\
$(\Delta / \sigma)_{\max }$ final cycle & 0.001 \\
$(\Delta \rho)_{\max }$ & 0.18 e $\AA^{-3}$ \\
$(\Delta \rho)_{\min }$ & $-0.22 \AA^{-3}$ \\
Measurement & Enraf-Nonius CAD4 \\
Program system & Enraf-Nonius Structure Determination \\
& Package \\
Structure Determination & SHELXS-97 \\
Refinement & full-matrix: SHELXL-97 \\
\hline
\end{tabular}




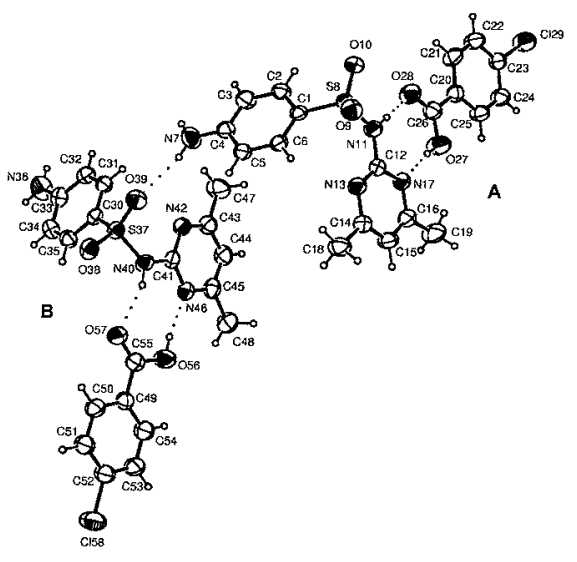

Fig. 2 ORTEP drawing of the asymmetric unit at the $40 \%$ probability level.

Fourier maps and subsequently added at idealized positions in a riding model with $U_{\text {iso }}$ set at $1.2-1.5$ times those of their parent atoms. All methyl $\mathrm{H}$ atoms were found to be disordered over two orientations, and were modeled accordingly. All non- $\mathrm{H}$ atoms were treated anisotropically. Crystal data and refinement details are listed in Table 1.

The two crystallographically independent co-crystal units A, B (Fig. 2) display the same type of molecular association, namely complementary hydrogen bonding between the carboxyl group of the acid molecule and the amido $\mathrm{N}$ atom and a pyrimidinyl $\mathrm{N}$ atom of sulfadimidine, giving rise to the $R_{2}^{2}(8)$ motif, which is common to the co-crystal series. ${ }^{2}$ The bond lengths and bond angles for the independent sulfadimidine molecules are virtually identical (Table 2), but the primary torsion angles listed indicate their significantly different conformations. In both of the acid molecules, the $-\mathrm{COOH}$ group is nearly coplanar with the phenyl ring.

The hydrogen-bonding parameters in the $R_{2}^{2}(8)$ system are of primary interest here. In co-crystal unit $\mathrm{A}$, the hydrogen bond $\mathrm{N}-\mathrm{H} \cdots \mathrm{O}$ has $\mathrm{N} \cdots \mathrm{O}=2.846(3) \AA$ and the $\mathrm{O}-\mathrm{H} \cdots \mathrm{N}$ bond has $\mathrm{O} \cdots \mathrm{N}=$ 2.666(3) $\AA$. The corresponding distances in the co-crystal unit B are $\mathrm{N} \cdots \mathrm{O}=2.797(3) \AA$ and $\mathrm{O} \cdots \mathrm{N}=2.670(3) \AA$. Therefore, in this co-crystal, while there is no significant difference between the $\mathrm{O} \cdots \mathrm{N}$ distances, the $\mathrm{N} \cdots \mathrm{O}$ distances in units $\mathrm{A}$ and $\mathrm{B}$ differ by $\sim 12 \sigma(\sigma=$ combined e.s.d. $)$. Since the latter hydrogen bonds are chemically identical, this significant difference can only be attributed to packing effects in the crystal, which also result in different conformations of the drug molecule in units A and B (It should be added that the four distances cited above are unaffected by the mode of $\mathrm{N}-\mathrm{H}$ hydrogen atom modelling employed, i.e. free $\mathrm{H}$ atom refinement, or the idealised trigonal geometry applied based on $\Delta F$ map evidence).

The above finding is sufficient evidence to indicate that hydrogen-bonded distances, as measures of strengths of interactions between binding partners in co-crystals, may be governed not only by inherent differences in the nature of the co-crystallizing partner molecules (as reflected in e.g. $\mathrm{p} K_{\mathrm{a}}$ differences), but also by crystal packing. In an earlier study, it was in fact pointed out that for a series of seven sulfadimidine co-crystal analogs in this series, with acid partner $\mathrm{p} K_{\mathrm{a}}$ values spanning the range of $2.89-6.97$, the $\mathrm{N} \cdots \mathrm{O}$ and $\mathrm{O} \cdots \mathrm{N}$ distances spanned the respective ranges of $2.779(3)-2.841(4)$ and $2.639(3)-2.724(4) \AA$. In this series, the maximum and
Table 2 Selected bond distances $(\AA)$, angles $\left(^{\circ}\right)$ and torsion angles $\left({ }^{\circ}\right)$

\begin{tabular}{llll}
$\mathrm{S} 8-\mathrm{O} 9$ & $1.424(2)$ & $\mathrm{S} 37-\mathrm{O} 39$ & $1.424(1)$ \\
$\mathrm{S} 8-\mathrm{O} 10$ & $1.429(2)$ & $\mathrm{S} 37-\mathrm{O} 38$ & $1.427(2)$ \\
$\mathrm{S} 8-\mathrm{N} 11$ & $1.639(2)$ & $\mathrm{S} 37-\mathrm{N} 40$ & $1.637(1)$ \\
$\mathrm{N} 13-\mathrm{C} 14$ & $1.345(3)$ & $\mathrm{N} 42-\mathrm{C} 43$ & $1.341(3)$ \\
$\mathrm{N} 17-\mathrm{C} 16$ & $1.341(3)$ & $\mathrm{N} 46-\mathrm{C} 45$ & $1.345(3)$ \\
$\mathrm{C} 12-\mathrm{N} 13$ & $1.320(3)$ & $\mathrm{C} 41-\mathrm{N} 42$ & $1.325(3)$ \\
$\mathrm{C} 12-\mathrm{N} 17$ & $1.336(3)$ & $\mathrm{C} 41-\mathrm{N} 46$ & $1.339(3)$ \\
$\mathrm{C} 4-\mathrm{N} 7$ & $1.361(3)$ & $\mathrm{C} 33-\mathrm{N} 36$ & $1.355(4)$ \\
$\mathrm{C} 26-\mathrm{O} 27$ & $1.305(3)$ & $\mathrm{C} 55-\mathrm{O} 56$ & $1.309(3)$ \\
$\mathrm{C} 26-\mathrm{O} 28$ & $1.216(3)$ & $\mathrm{C} 55-\mathrm{O} 57$ & $1.215(3)$ \\
$\mathrm{C} 23-\mathrm{C} 129$ & $1.733(2)$ & $\mathrm{C} 52-\mathrm{Cl} 158$ & $1.729(3)$ \\
& & & \\
$\mathrm{C} 12-\mathrm{N} 13-\mathrm{C} 14$ & $116.1(2)$ & $\mathrm{C} 41-\mathrm{N} 42-\mathrm{C} 43$ & $116.1(2)$ \\
$\mathrm{C} 12-\mathrm{N} 17-\mathrm{C} 16$ & $116.5(2)$ & $\mathrm{C} 41-\mathrm{N} 46-\mathrm{C} 45$ & $116.4(2)$ \\
$\mathrm{S} 8-\mathrm{N} 11-\mathrm{C} 12$ & $127.7(2)$ & $\mathrm{S} 37-\mathrm{N} 40-\mathrm{C} 41$ & $124.7(1)$ \\
$\mathrm{C} 1-\mathrm{S} 8-\mathrm{N} 11$ & $107.5(1)$ & $\mathrm{C} 30-\mathrm{S} 37-\mathrm{N} 40$ & $106.6(1)$ \\
$\mathrm{O} 9-\mathrm{S} 8-\mathrm{O} 10$ & $118.9(1)$ & $\mathrm{0} 38-\mathrm{S} 37-\mathrm{O} 39$ & $118.1(1)$ \\
$\mathrm{O} 27-\mathrm{C} 26-\mathrm{O} 28$ & $123.4(2)$ & $\mathrm{056}-\mathrm{C} 55-\mathrm{O} 57$ & $123.3(2)$ \\
& & & \\
$\mathrm{C} 2-\mathrm{C} 1-\mathrm{S} 8-\mathrm{N} 11$ & $-95.2(2)$ & $\mathrm{C} 35-\mathrm{C} 30-\mathrm{S} 37-\mathrm{N} 40$ & $73.6(1)$ \\
$\mathrm{C} 1-\mathrm{S} 8-\mathrm{N} 11-\mathrm{C} 12$ & $-68.3(2)$ & $\mathrm{C} 30-\mathrm{S} 37-\mathrm{N} 40-\mathrm{C} 41$ & $56.1(1)$ \\
$\mathrm{S} 8-\mathrm{N} 11-\mathrm{C} 12-\mathrm{N} 13$ & $0.0(3)$ & $\mathrm{S} 37-\mathrm{N} 40-\mathrm{C} 41-\mathrm{N} 42$ & $16.2(2)$ \\
$\mathrm{C} 21-\mathrm{C} 20-\mathrm{C} 26-\mathrm{O} 28$ & $3.4(4)$ & $\mathrm{C} 50-\mathrm{C} 49-\mathrm{C} 55-\mathrm{O} 57$ & $-5.1(3)$ \\
$\mathrm{C} 25-\mathrm{C} 20-\mathrm{C} 26-\mathrm{O} 27$ & $0.4(4)$ & $\mathrm{C} 54-\mathrm{C} 49-\mathrm{C} 55-\mathrm{O} 56$ & $-3.7(3)$ \\
\hline
\end{tabular}

minimum $\mathrm{N}$... $\mathrm{O}$ distances in the $\mathrm{N}-\mathrm{H} \cdots \mathrm{O}$ hydrogen bonds thus differ by $\sim 12 \sigma$. This, we note, is of the same order as the difference between the two independent $\mathrm{N}$... O distances reported here for co-crystal 1, clearly showing that the subtle influence that partner $\mathrm{p} K_{\mathrm{a}}$ differences may confer on them may be overshadowed by gross differences resulting from packing effects. It follows that, unless such co-crystals display a strong measure of crystal isostructurality, ${ }^{4}$ conformational and/or crystal packing differences can render the type of attempted correlation referred to earlier meaningless. ${ }^{3}$

The crystal of $\mathbf{1}$ is stabilised by four additional intermolecular $\mathrm{N}-\mathrm{H} \cdots \mathrm{O}$ hydrogen bonds involving the $-\mathrm{NH}_{2}$ functions of sulfadimidine as donors, and sulfonyl or acid carbonyl oxygen

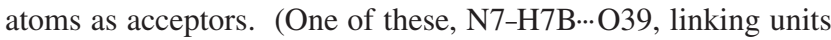
$\mathrm{A}$ and $\mathrm{B}$, is shown in Fig. 2). The $\mathrm{N}$... O distance range for these H-bonds is $3.006(3)-3.281(3) \AA$. The shortest $\pi$-stacking interaction in the crystal of $\mathbf{1}, 3.648(2) \AA$, is that between the phenyl ring of a $p$-chlorobenzoic acid molecule and a pyrimidine ring of a sulfadimidine molecule.

\section{Acknowledgements}

MRC thanks the University of Cape Town for financial assistance. This work is based on research supported by the National Research Foundation. Any opinion, findings and conclusions or recommendations expressed in this material are those of the authors, and therefore the NRF does not accept any liability in regard thereto.

\section{References}

1. M. L. Peterson, M. B. Hickey, M. J. Zaworotko, and O. Almarsson, J. Pharm. Sci., 2006, 9, 317.

2. M. R. Caira, Mol. Pharmaceutics, 2007, 4, 310.

3. M. R. Caira. J. Crystallogr. Spectrosc. Res., 1992, 22, 193.

4. L. Fabian and A. Kalman, Acta Crystallogr., 1999, B55, 1099. 